Open Access

\title{
Updated prevalence rates of overweight and obesity in 11- to 17-year-old adolescents in Germany. Results from the telephone-based KiGGS Wave 1 after correction for bias in self-reports
}

\author{
Anna-Kristin Brettschneidera ${ }^{1 *}$, Angelika Schaffrath Rosario ${ }^{1}$, Ronny Kuhnert ${ }^{1}$, Steffen Schmidt ${ }^{2}$, Susanna Wiegand ${ }^{3}$, \\ Ute Ellert $^{1 \dagger}$ and Bärbel-Maria Kurth ${ }^{1 \dagger}$
}

\begin{abstract}
Background: The nationwide "German Health Interview and Examination Survey for Children and Adolescents" (KiGGS), conducted in 2003-2006, showed an increase in the prevalence rates of overweight and obesity compared to the early 1990s, indicating the need for regularly monitoring. Recently, a follow-up_KiGGS Wave 1 (2009-2012)—was carried out as a telephone-based survey, providing self-reported height and weight. Since self-reports lead to a bias in prevalence rates of weight status, a correction is needed. The aim of the present study is to obtain updated prevalence rates for overweight and obesity for 11- to 17-year olds living in Germany after correction for bias in self-reports.
\end{abstract}

Methods: In KiGGS Wave 1, self-reported height and weight were collected from 4948 adolescents during a telephone interview. Participants were also asked about their body perception. From a subsample of KiGGS Wave 1 participants, measurements for height and weight were collected in a physical examination. In order to correct prevalence rates derived from self-reports, weight status categories based on self-reported and measured height and weight were used to estimate a correction formula according to an established procedure under consideration of body perception. The correction procedure was applied and corrected rates were estimated.

Results: The corrected prevalence of overweight, including obesity, derived from KiGGS Wave 1, showed that the rate has not further increased compared to the KiGGS baseline survey (18.9\% vs. $18.8 \%$ based on the German reference).

Conclusion: The rates of overweight still remain at a high level. The results of KiGGS Wave 1 emphasise the significance of this health issue and the need for prevention of overweight and obesity in children and adolescents.

Keywords: Overweight, Obesity, Prevalence, Adolescents, KiGGS Wave 1

\section{Background}

The "German Health Interview and Examination Survey for Children and Adolescents" (KiGGS), which is part of the health monitoring system of the Robert Koch Institute, regularly collects health data from a nationwide, representative sample of children and adolescents.

\footnotetext{
*Correspondence: BrettschneiderA@rki.de

${ }^{\dagger}$ Equal contributors

'Department of Epidemiology and Health Monitoring, Robert Koch Institute, General-Pape-Str. 62-66, 12101 Berlin, Germany

Full list of author information is available at the end of the article
}

In the KiGGS baseline survey, which was an examination survey carried out in 2003-2006, height and weight of the participants were measured [1]. It was found that the prevalence rate of overweight, including obesity, in children and adolescents aged 3 to 17 years, had risen by about $50 \%$, and obesity had doubled compared to the early 1990s. The prevalence of overweight, including obesity, in adolescents aged 11 to 17 years had almost doubled, and the prevalence of obesity had nearly tripled [2].
() Biomed Central

(c) 2015 Brettschneidera et al. Open Access This article is distributed under the terms of the Creative Commons Attribution 4.0 International License (http://creativecommons.org/licenses/by/4.0/), which permits unrestricted use, distribution, and reproduction in any medium, provided you give appropriate credit to the original author(s) and the source, provide a link to the Creative Commons license, and indicate if changes were made. The Creative Commons Public Domain Dedication waiver (http://creativecommons.org/publicdomain/zero/1.0/) applies to the data made available in this article, unless otherwise stated. 
Currently, a stabilisation of the prevalence rates of overweight and obesity in children and adolescents in developed countries has been reported [3], while the rates are still increasing in developing countries [4]. In Germany between 2004 and 2008, a significant downward trend for younger boys and girls between 4 to 7 years of age could be seen in one study, whereas for older children and adolescents aged 8 to 16 years, a plateau seems to have been reached [5]. The compulsory school enrolment examination showed a stagnation, or even a decrease, in the prevalence of overweight and obese children at the age of school entry [6].

However, the rates remain at a high level and still represent a significant health issue that requires regular monitoring. Recently, a follow-up of the KiGGS study-KiGGS Wave 1 (2009-2012)-was carried out as a telephonebased survey, providing self-reported height and weight from 11- to 17-year-old adolescents [7]. Analyses of selfreported height and weight data can underestimate the prevalence rates of overweight and obesity [8-11]. For the KiGGS baseline, it was shown that underreporting is stronger in girls than in boys, and is also stronger in overweight/obese individuals compared to normal-weight adolescents. Body perception emerged as a main predictor of the bias in self-reported height and weight, next to gender and weight status $[8,10,12]$. Therefore, either an individual correction of self-reported height and weight in order to determine the weight status or a correction of the prevalence rates of weight status derived from self-reports is necessary. Some of the authors developed and validated different approaches of correction based on self-reported and measured data of the KiGGS baseline survey [10, 13]. The correction procedure which directly corrects prevalence rates derived from self-reports by considering body perception [10], showed the smallest deviation from prevalence rates derived from measured data [13]. Therefore, this procedure [10] was replicated in the present paper in order to derive a new correction formula for KiGGS Wave 1, since the patterns of underreporting might vary over time. It has also been applied or replicated, respectively in other German studies in order to get improved prevalence estimates $[14,15]$.

A subsample of the KiGGS Wave 1 participants took part in the so-called 'Motorik Modul' (MoMo) focusing on motor fitness. For those participants, measurements of height and weight were collected [16]. The measurements from this small subsample provided the opportunity to improve the estimated prevalence rates of overweight and obesity derived from self-reported values of the representative KiGGS Wave 1 sample.

The aim of the present study was to obtain updated prevalence rates for overweight and obesity in 11- to 17 -year olds living in Germany by applying the correction method described in Kurth and Ellert's research [10].

\section{Methods}

\section{Study population}

The analyses presented are based on the data from KiGGS Wave 1. The goals, concept and design of KiGGS have been described elsewhere [1, 7, 17]. KiGGS Wave 1 (2009-2012), the follow-up of the KiGGS baseline study (2003-2006), was carried out as a telephone-based survey. An essential aim of KiGGS is to regularly provide population-based cross-sectional data on the health situation of children and adolescents aged 0-17 years living in Germany. Amongst others, the study population of KiGGS Wave 1 consists of re-invited participants from the baseline study (KiGGS cohort). A total of 5258 reinvited children and adolescents aged 11 to 17 years participated in KiGGS Wave 1 (response $73.9 \%$ ). The net sample was compared with the resident German population regarding particular population characteristics and an analysis of the relationship between the reparticipation rate and certain characteristics collected in the baseline study, suggesting a mostly unbiased sample after taking the sample weights into account [7].

Trained study staff conducted standardised telephone interviews with adolescents aged 11 or older. For further information (e.g. socioeconomic status) and to collect information about the younger participants, parents of children and adolescents aged 0-17 years were interviewed. The software product Voxco Version 5.4.4.5 (Voxco Inc., Montréal QC, Canada) was used to manage the calls and collect the data. A written informed consent from parents or caregivers was required prior to the interviews. The Federal Office for Data Protection and the ethics committee of the Charité Medical University Berlin approved the survey.

Additionally, the 'Motorik Modul' (MoMo), which collected data on motor fitness and physical activity of children and adolescents aged 4 to 17 years in a physical examination, was part of KiGGS Wave 1 [16]. At the end of the telephone interview, approximately half of the KiGGS Wave 1 subjects were asked to participate in MoMo. If they gave their consent, they received information material and were contacted to make an appointment for the physical examination.

\section{Self-reports and anthropometric measurements}

In the telephone interview, adolescents were asked to report their height (without shoes) and weight (without clothes) to an accuracy of $1 \mathrm{~cm}$ or $1 \mathrm{~kg}$, respectively.

Trained staff, in the physical examination of the 'Motorik Modul', took anthropometric measurements. Body height was measured without shoes to an accuracy of $0.1 \mathrm{~cm}$ using a portable stadiometer. Body weight, while the participant was wearing just underwear, was measured to the nearest $0.1 \mathrm{~kg}$ using a calibrated electronic scale. 
Body mass index (BMI) in $\mathrm{kg} / \mathrm{m}^{2}$ was calculated both from self-reported and from measured data. Weight status was determined using age- and gender-specific cutoffs for strong underweight ( $<3$ rd percentile), underweight ( $\geq 3$ rd percentile to $<10$ th percentile), normal weight ( $\geq 10$ th percentile to $\leq 90$ th percentile), overweight ( $>90$ th percentile to $<97$ th percentile) and obese $(\geq 97$ th percentile), based on the national German reference [18].

\section{Body perception}

Each adolescent's body perception (BP) was examined by asking the following questions in the telephone interview: 'Do you think you are ...' 'much too thin', 'a bit too thin', 'exactly the right weight', 'a bit too fat', or 'much too fat'? [19]. Responses were classified into the following categories: (1) 'too thin' (summarising 'much too thin' and 'a bit too thin'), (2) 'right weight', and (3) 'too fat' (summarising 'a bit too fat' and 'much too fat').

\section{Socioeconomic status}

The socioeconomic status of the participants was assessed by a multidimensional index score. The parents were asked to report their education and occupational qualifications, occupational status, and net income. This information was used to calculate the socioeconomic sum score, which was categorised into the following groups: (1) low, (2) moderate, and (3) high socioeconomic status [20].

\section{Statistical analysis/correction procedure}

The analyses focused on 2509 boys and 2446 girls, aged 11 to 17 years, who were interviewed in KiGGS Wave 1. Cases with missing values for body perception (seven cases) were excluded, which led to a total sample size of 4948 adolescents ( 2505 boys and 2443 girls).

Measured height and weight from MoMo were available from 899 boys and 872 girls aged 11 to 17 years at the time of the KiGGS Wave 1 telephone interview. Due to the time lag between KiGGS Wave 1 and MoMo, there were 36 cases that were 17 years old at the time of the KiGGS Wave 1 telephone interview, but turned 18 when they participated in MoMo. These cases were included in the correction procedure. MoMo participants who did not give information about their body perception in the telephone interview were excluded from the correction procedure. Participants with a time lag between the telephone interview and the examination part of MoMo of greater than 3 months (90 days) were also excluded from the analyses. For the correction procedure of prevalence rates derived from self-reports of KiGGS Wave 1, weight status derived from height and weight measured in MoMo was thus available for 826 boys and 814 girls.
In previous analyses with data from KiGGS baseline, which provide both self-reported and measured values, correction of prevalence rates for weight status derived from self-reports with Kurth and Ellert's [10] formula showed satisfying results [13]. Therefore, the correction procedure developed by Kurth and Ellert with data of KiGGS baseline (formula 16) [10] (i.e. the statistical procedure of directly correcting the prevalence rates) was replicated here in order to derive a new correction formula for KiGGS Wave 1. The derivation of a new correction formula was necessary since the amount and patterns of underreporting might vary (1) over time; and (2) with the change of survey mode (face-to-face interview in KiGGS baseline vs. telephone interview in KiGGS Wave 1). For the correction procedure, the prevalence based on measured height and weight from MoMo was used, as well as the information regarding individual body perception.

Let $R_{k}, k=1$...3 denote the prevalence of body perception (BP) category $k$ in KiGGS Wave 1, i.e. $R_{k}=P(B P=k), k=$ $1 . . .3$ ('too thin', 'right weight', 'too fat'). $Q_{j k}$ is the uncorrected prevalence, based on self-reported height and weight in KiGGS Wave 1, of weight status category $j$ in the group of adolescents with body perception $k$, i.e. it is the conditional probability

$$
\begin{aligned}
& Q_{j k}=P\left(B M I_{\text {reported }} \in I_{j} \mid B P=k\right)(j=1 \ldots 6 ; k=1 \ldots 3), \\
& \text { with } \\
& I_{1}=\text { Extremely underweight }(<P 3) \\
& I_{2}=\text { Underweight }(\geq P 3-<P 10) \\
& I_{3}=\text { Normal Weight }(\geq P 10-<P 90) \\
& I_{4}=\text { Overweight }(\geq P 90-<P 97) \\
& I_{5}=\text { Obese }(\geq P 97) \\
& I_{6}=\text { Self-reported height and/or weight missing }
\end{aligned}
$$

Here, category $I_{6}$ was newly introduced to represent adolescents with missing values for weight status derived from self-reports, but with available information on weight status derived from measurements and body perception.

The corrected prevalence rate for weight status category $j$ in KiGGS Wave $1, P\left(\mathrm{BMI}_{\text {corrected }} \in \mathrm{I}_{i}\right)$, is then given by:

$$
P\left(\mathrm{BMI}_{\text {corrected }} \in \mathrm{I}_{i}\right)=\sum_{k=1}^{3}\left[\sum_{j=1}^{6} \alpha_{i j k} Q_{j k}\right] R_{k}(i=1 \ldots 5),
$$

with $I_{1} \ldots I_{5}$ defined as above, where the relationship between measured and self-reported values is captured by the factors $\alpha_{i j k}$, which are the conditional probabilities for measured weight status category $i$ in the group of adolescents with body perception $k$ and weight status category $j$ based on self-reported height and weight, i.e. $\propto_{i j k}=P\left(B M I_{\text {measured }} \in I_{i} \mid B M I_{\text {reported }} \in I_{j}, B P=k\right)$, with $I_{1} \ldots I_{6}$ defined as above. 
The factors $\alpha_{i j k}$ were determined in the MoMo subsample. Weight status based on measured values was taken from MoMo, whereas information about weight status based on self-reports and body perception was taken from the telephone interview in KiGGS Wave 1. Then, $95 \%$ confidence intervals for the corrected prevalence rates were estimated via a bootstrap procedure with 2000 replicates by resampling 166 sample points with replacement from the 167 original sample points [21] and using the 2.5 and $97.5 \%$ quantiles of the bootstrapped distribution as the confidence limits. These confidence intervals include the effect of the additional uncertainty introduced by the correction procedure.

All analyses, including the correction procedure, were performed with the survey procedures of SAS release 9.4 (SAS Institute Inc., Cary, NC, USA, 2012), taking sample weights and the clustering in sample points into account. The analyses were both conducted separately for boys and girls and for the total sample. The sample weights were used to correct for possible deviations of the sample from the population structure (as of December 31, 2010) with regard to age, gender, region, parental education, and nationality (whether or not they were German). Furthermore, they included a correction for selective dropout based on a logistic regression modelling of the reparticipation probability [7].

For a comparison of the corrected prevalence rates derived from KiGGS Wave 1 with the prevalence rates from the KiGGS baseline study, the latter ones were recalculated using sample weights analogous to KiGGS Wave 1 (i.e. using the population structure as of December 31, 2010 and including parental education in the calculation of the sample weights) [7].

\section{Results}

Table 1 illustrates the characteristics for both the study population of KiGGS Wave 1 with data derived from the telephone interview and for the subsample of KiGGS Wave 1 that participated in the MoMo physical examination. Prevalence rates derived from self-reported height and weight in the KiGGS sample were $7.8 \%$ for overweight and $4.0 \%$ for obesity. The rates based on self-reports from the MoMo subsample were similar (overweight: $8.0 \%$; obesity: $3.8 \%$ ). The conditional probabilities $\alpha_{i j k}$ required for the correction procedure are displayed in Table 2. Using $\alpha_{i j k}$ and $Q_{j k}$ from Table 2 and $R_{k}$ from Table 1, the corrected prevalence rates of weight status were estimated for KiGGS Wave 1 using formula (I).

Table 1 Description of the study population of KiGGS Wave 1 and the subsample of MoMo

\begin{tabular}{|c|c|c|c|c|c|c|c|c|c|c|c|c|}
\hline & \multicolumn{6}{|c|}{ KiGGS wave 1} & \multicolumn{6}{|c|}{ MoMo subsample } \\
\hline & \multicolumn{2}{|c|}{ All $(n=4948)$} & \multicolumn{2}{|c|}{ Boys $(n=2505)$} & \multicolumn{2}{|c|}{ Girls $(n=2443)$} & \multicolumn{2}{|c|}{ All $(n=1640)$} & \multicolumn{2}{|c|}{ Boys $(n=826)$} & \multicolumn{2}{|c|}{ Girls $(n=814)$} \\
\hline & $\overline{N^{a}}$ & $\%^{b}$ & $\overline{N^{a}}$ & $\%^{b}$ & $\overline{N^{a}}$ & $\%^{\mathrm{b}}$ & $\overline{N^{a}}$ & $\%^{b}$ & $\overline{N^{a}}$ & $\%^{\mathrm{b}}$ & $\overline{N^{a}}$ & $\%^{\mathrm{b}}$ \\
\hline \multicolumn{13}{|l|}{ Age } \\
\hline $11-13$ years & 2155 & 43.0 & 1108 & 43.4 & 1047 & 42.6 & 809 & 47.0 & 405 & 45.0 & 404 & 49.2 \\
\hline $14-17$ years & 2793 & 57.0 & 1397 & 56.6 & 1396 & 57.4 & 831 & 53.0 & 421 & 55.0 & 410 & 50.8 \\
\hline \multicolumn{13}{|c|}{ Weight status derived from uncorrected self-reported height and weight $\left(\mathrm{Q}_{\mathrm{i}}\right)$} \\
\hline Extremely underweight & 159 & 3.4 & 68 & 2.9 & 91 & 3.9 & 58 & 4.2 & 24 & 3.1 & 34 & 5.4 \\
\hline Underweight & 324 & 6.5 & 141 & 5.7 & 183 & 7.3 & 107 & 6.4 & 45 & 5.4 & 62 & 7.6 \\
\hline Normal weight & 3608 & 78.3 & 1826 & 78.8 & 1782 & 77.9 & 1223 & 77.5 & 623 & 77.8 & 600 & 77.2 \\
\hline Overweight & 292 & 7.8 & 165 & 7.8 & 127 & 7.7 & 88 & 8.0 & 49 & 8.5 & 39 & 7.5 \\
\hline Obese & 152 & 4.0 & 94 & 4.8 & 58 & 3.2 & 41 & 3.8 & 25 & 5.2 & 16 & 2.3 \\
\hline Missing value & 413 & & 211 & & 202 & & 123 & & 60 & & 63 & \\
\hline \multicolumn{13}{|l|}{ Body perception $\left(R_{k}\right)$} \\
\hline Too thin & 732 & 14.9 & 468 & 19.1 & 264 & 10.5 & 255 & 15.5 & 157 & 17.7 & 98 & 13.1 \\
\hline Right weight & 2920 & 56.3 & 1438 & 55.2 & 1482 & 57.3 & 1002 & 57.3 & 504 & 58.9 & 498 & 55.5 \\
\hline Too fat & 1296 & 28.9 & 599 & 25.6 & 697 & 32.2 & 383 & 27.3 & 165 & 23.4 & 218 & 31.4 \\
\hline \multicolumn{13}{|l|}{ Socio-economic status } \\
\hline Low & 590 & 22.6 & 316 & 24.1 & 274 & 20.9 & 159 & 22.7 & 81 & 23.3 & 78 & 21.9 \\
\hline Moderate & 3118 & 59.7 & 1552 & 57.8 & 1566 & 61.7 & 1069 & 60.7 & 532 & 59.8 & 537 & 61.7 \\
\hline High & 1178 & 17.7 & 608 & 18.0 & 570 & 17.3 & 411 & 16.6 & 212 & 16.8 & 199 & 16.4 \\
\hline Missing value & 62 & & 29 & & 33 & & 1 & & 1 & & & \\
\hline
\end{tabular}


Table 2 Weight status categories derived from measured height and weight according to weight status categories derived from reported values and according to body perception

\begin{tabular}{|c|c|c|c|c|c|c|c|c|c|c|c|c|c|c|c|c|c|c|c|c|c|}
\hline \multirow{3}{*}{$\alpha_{i j k}$} & \multicolumn{7}{|l|}{ All } & \multicolumn{7}{|l|}{ Boys } & \multicolumn{7}{|l|}{ Girls } \\
\hline & \multicolumn{6}{|c|}{$\mathrm{BMI}_{\text {reported }}$} & \multirow[t]{2}{*}{$\underline{Q_{j k}}$} & \multicolumn{6}{|c|}{$\mathrm{BMI}_{\text {reported }}$} & \multirow[t]{2}{*}{$\underline{Q_{j k}}$} & \multicolumn{6}{|c|}{$\mathrm{BMI}_{\text {reported }}$} & \multirow[t]{2}{*}{$\underline{Q_{j k}}$} \\
\hline & $\mathrm{I}_{1}$ & $\mathrm{I}_{2}$ & $I_{3}$ & $\mathrm{I}_{4}$ & $I_{5}$ & $I_{6}$ & & $\mathrm{I}_{1}$ & $\mathrm{I}_{2}$ & $\mathrm{I}_{3}$ & $\mathrm{I}_{4}$ & $I_{5}$ & $I_{6}$ & & $\mathrm{I}_{1}$ & $\mathrm{I}_{2}$ & $I_{3}$ & $\mathrm{I}_{4}$ & $I_{5}$ & $I_{6}$ & \\
\hline \multicolumn{8}{|l|}{$\mathrm{BMI}_{\text {measured }}$} & \multicolumn{14}{|c|}{ Body perception $=1$ (too thin) } \\
\hline$l_{1}$ & $51.4 \%$ & $9.7 \%$ & $2.4 \%$ & & & $12.8 \%$ & $13.0 \%$ & $61.1 \%$ & $19.2 \%$ & $2.3 \%$ & & & $15.8 \%$ & $9.8 \%$ & $43.0 \%$ & $3.1 \%$ & $2.8 \%$ & & & $6.7 \%$ & $19.1 \%$ \\
\hline $\mathrm{I}_{2}$ & $21.7 \%$ & $49.9 \%$ & $11.0 \%$ & & & $14.5 \%$ & $19.5 \%$ & $31.8 \%$ & $40.5 \%$ & $14.3 \%$ & & & $8.5 \%$ & $17.2 \%$ & $13.1 \%$ & $56.5 \%$ & $4.9 \%$ & & & $26.7 \%$ & $23.7 \%$ \\
\hline $\mathrm{l}_{3}$ & $26.9 \%$ & $40.4 \%$ & $86.1 \%$ & & & $72.7 \%$ & $58.6 \%$ & $7.1 \%$ & $40.3 \%$ & $82.9 \%$ & & & $75.7 \%$ & $62.2 \%$ & $43.9 \%$ & $40.4 \%$ & $92.3 \%$ & & & $66.6 \%$ & $51.8 \%$ \\
\hline $\mathrm{I}_{4}$ & & & $0.4 \%$ & & & & & & & $0.6 \%$ & & & & & & & & & & & \\
\hline \multicolumn{22}{|l|}{$\mathrm{I}_{5}$} \\
\hline \multirow[t]{2}{*}{$I_{6}$} & - & - & - & - & - & - & $8.9 \%$ & - & - & - & - & - & - & $10.8 \%$ & - & - & - & - & - & - & $5.4 \%$ \\
\hline & & & & & & & & \multicolumn{14}{|c|}{ Body perception $=2$ (right weight) } \\
\hline$I_{1}$ & $11.9 \%$ & $1.5 \%$ & $0.1 \%$ & & & $0.9 \%$ & $1.9 \%$ & $30.9 \%$ & $4.3 \%$ & $0.2 \%$ & & & & $1.3 \%$ & $5.9 \%$ & & & & & $1.9 \%$ & $2.6 \%$ \\
\hline $\mathrm{I}_{2}$ & $20.8 \%$ & $26.6 \%$ & $1.0 \%$ & & & $1.0 \%$ & $5.1 \%$ & $12.9 \%$ & $38.2 \%$ & $0.9 \%$ & & & & $3.3 \%$ & $23.4 \%$ & $20.2 \%$ & $1.1 \%$ & & & $2.1 \%$ & $7.0 \%$ \\
\hline$I_{3}$ & $63.5 \%$ & $69.9 \%$ & $95.3 \%$ & $40.7 \%$ & & $86.8 \%$ & $82.7 \%$ & $56.2 \%$ & $57.6 \%$ & $93.8 \%$ & $57.4 \%$ & & $78.7 \%$ & $84.2 \%$ & $65.8 \%$ & $76.6 \%$ & $96.9 \%$ & & & $95.7 \%$ & $81.3 \%$ \\
\hline $\mathrm{I}_{4}$ & $3.8 \%$ & & $3.5 \%$ & $45.2 \%$ & $63.5 \%$ & $0.2 \%$ & $1.8 \%$ & & & $4.8 \%$ & $42.6 \%$ & $73.0 \%$ & & $2.7 \%$ & $5.0 \%$ & & $1.9 \%$ & $51.6 \%$ & & $0.4 \%$ & $1.0 \%$ \\
\hline$I_{5}$ & & $2.0 \%$ & $0.2 \%$ & $14.0 \%$ & $36.5 \%$ & $11.1 \%$ & $0.2 \%$ & & & $0.3 \%$ & & $27.1 \%$ & $21.3 \%$ & $0.3 \%$ & & $3.2 \%$ & $0.1 \%$ & $48.4 \%$ & $100.0 \%$ & & \\
\hline \multirow[t]{2}{*}{$I_{6}$} & - & - & - & - & - & - & $8.2 \%$ & - & - & - & - & - & - & $8.3 \%$ & - & - & - & - & - & - & $8.1 \%$ \\
\hline & & & & & & & & \multicolumn{14}{|c|}{ Body perception = 3 (too fat) } \\
\hline$l_{1}$ & & & & & & & $0.1 \%$ & & & & & & & $0.1 \%$ & & & & & & & $0.2 \%$ \\
\hline $\mathrm{I}_{2}$ & & & & & & $1.7 \%$ & $0.4 \%$ & & & & & & & $0.2 \%$ & & & & & & $2.6 \%$ & $0.5 \%$ \\
\hline$I_{3}$ & & $100.0 \%$ & $75.2 \%$ & $5.3 \%$ & & $23.1 \%$ & $54.2 \%$ & & $100.0 \%$ & $72.4 \%$ & $1.5 \%$ & & $21.1 \%$ & $50.0 \%$ & & & $77.0 \%$ & $8.3 \%$ & & $24.2 \%$ & $57.7 \%$ \\
\hline$I_{4}$ & $100.0 \%$ & & $18.4 \%$ & $49.3 \%$ & $3.2 \%$ & $19.7 \%$ & $20.8 \%$ & & & $23.2 \%$ & $65.1 \%$ & $5.0 \%$ & $9.0 \%$ & $21.8 \%$ & $100.0 \%$ & & $15.2 \%$ & $36.8 \%$ & & $25.6 \%$ & $19.9 \%$ \\
\hline$l_{5}$ & & & $6.4 \%$ & $45.4 \%$ & $96.8 \%$ & $55.5 \%$ & $12.2 \%$ & & & $4.4 \%$ & $33.4 \%$ & $95.0 \%$ & $69.9 \%$ & $16.2 \%$ & & & $7.8 \%$ & $54.9 \%$ & $100.0 \%$ & $47.5 \%$ & $9.0 \%$ \\
\hline$I_{6}$ & - & - & - & - & - & - & $12.3 \%$ & - & - & - & - & - & - & $11.7 \%$ & - & - & - & - & - & - & $12.8 \%$ \\
\hline
\end{tabular}

$B M I_{\text {measured: }}$ derived from measured height and weight collected in MoMo

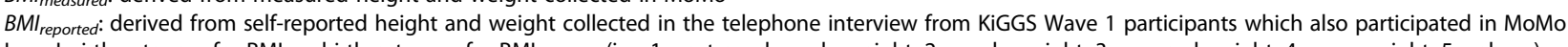

$\mathrm{I}_{1} \ldots \mathrm{I}_{5}$ : i-th category for BMI and j-th category for $\mathrm{BMI}_{\text {reported }}(\mathrm{i}$.e., $1=$ extremely underweight, $2=$ underweight, $3=$ normal weight, $4=$ overweight, $5=$ obese)

I $_{6}$ : Missing value for self-reported height and/or weight

$Q_{j k}$ Prevalence rates of weight status categories $j$ derived from self-reported height and weight according to body perception $=k$ in KiGGS Wave

$\alpha_{i j k}=P\left(B M I_{\text {measured }} \in I_{i} \mid B M I_{\text {reported }} \in I_{j}, B P=k\right)$ 
Prevalence rates of weight status based on selfreported values and the corrected prevalence rates for KiGGS Wave 1 are presented in Table 3. The correction procedure led to remarkably higher prevalence estimates of overweight and obesity, especially in girls, which underlines the importance of using a correction. The prevalence of overweight, including obesity, has not further increased compared to the KiGGS baseline survey (KiGGS baseline: 18.8 \% (95 \% CI 17.7-20.0) vs. KiGGS Wave 1: 18.9 \% (95 \% CI 16.4-21.2)) (Fig. 1).

After correction, $8.9 \%$ (95 \% CI 7.0-10.9) of the adolescents were overweight (boys: $10.2 \%$ (95\% CI 7.8-12.8); girls: $7.6 \%$ (95 \% CI 5.3-10.4)) and $10.0 \%$ (95 \% CI 8.0-11.7) obese (boys: $9.6 \%$ (95 \% CI 7.2-11.8); girls: $10.3 \%$ (95 \% CI 7.3-13.2)). In comparison to prevalence from the KiGGS baseline survey (2003-2006), which was based on measured values, there is a slight, but not significant, decrease in the prevalence rate of overweight (KiGGS baseline: $9.9 \%$ (95 \% CI 9.1-10.8) vs. KiGGS Wave 1: 8.9 \% (95 \% CI 7.0-10.9)), whereas for obesity, a slight non-significant increase is seen (KiGGS baseline: 8.9 \% (95 \% CI 8.0-9.9) vs. KiGGS Wave 1: 10.0 \% (95\% CI 8.0-11.7)). Gender differences are seen for overweight, but not for obesity. In girls, the prevalence of overweight decreased (n.s.), whereas in boys, it remained nearly unchanged (Table 3).

\section{Discussion}

The corrected prevalence rates derived from KiGGS Wave 1 for overweight, including obesity, in adolescents aged 11 to 17 years in Germany was 18.9 \% (boys: $19.8 \%$; girls: $17.9 \%$ ). In comparison to the prevalence from the KiGGS baseline survey (2003-2006) (total: $18.8 \%$ ), a stagnation in the prevalence of overweight, including obesity, has been reached. Thus the previously reported plateauing of the prevalence of overweight, including obesity, in adolescents living in Germany [5] can be confirmed by this current nationwide sample. However, there is still a slight tendency for increases (n.s.) in the obesity prevalence in both boys and girls. This indicates that in this age group, a higher percentage of those with overweight are obese compared to the rates from the KiGGS baseline survey, emphasising the significance of this health issue.

Similar results have been seen in the "German Health Interview and Examination Survey for Adults" (DEGS1), conducted in 2008-2011. DEGS1 showed, in comparison to studies from the 1990s, no further increase in the prevalence of overweight in women, whereas for men, a slight increase could be seen. However, the prevalence rates for obesity increased remarkably in both men and women, especially in young adults (aged 25 to 34 years) [22]. Similar trends have also been reported both for

Table 3 Comparison of prevalence rates derived from measured (KiGGS baseline), self-reported (KiGGS Wave 1), and corrected (KiGGS Wave 1) data in 11- to 17-year old adolescents in Germany

\begin{tabular}{|c|c|c|c|c|c|c|}
\hline \multirow[t]{2}{*}{ Weight status } & \multicolumn{2}{|c|}{$\mathrm{BMI}^{\mathrm{KiGGS} \text { baseline }}{ }_{\text {measured }}$} & \multicolumn{2}{|c|}{$\left.B M\right|^{\text {KiGGS1 }}{ }_{\text {reported }}$} & \multicolumn{2}{|c|}{$\mathrm{BMI}^{\mathrm{KiGGS1}}{ }_{\text {corrected }}$} \\
\hline & $\%$ & $95 \% \mathrm{Cl}$ & $\overline{\%}$ & $95 \% \mathrm{Cl}$ & $\%$ & $95 \% \mathrm{Cl}$ \\
\hline Boys & \multicolumn{2}{|c|}{$n=3477$} & \multicolumn{2}{|c|}{$n=2294$} & \multicolumn{2}{|c|}{$n=2505$} \\
\hline Extremely underweight & 2.3 & $1.7-3.0$ & 2.9 & $2.0-4.0$ & 2.7 & $1.6-4.2$ \\
\hline Underweight & 5.4 & $4.5-6.4$ & 5.9 & $4.7-7.3$ & 5.0 & $3.2-6.9$ \\
\hline Normal weight & 73.9 & $72.0-75.7$ & 78.7 & $75.9-81.3$ & 72.4 & $68.5-76.4$ \\
\hline Overweight & 10.1 & $8.9-11.3$ & 7.8 & $6.3-9.7$ & 10.2 & $7.8-12.8$ \\
\hline Obese & 8.4 & $7.2-9.7$ & 4.8 & $3.6-6.3$ & 9.6 & $7.2-11.8$ \\
\hline Girls & \multicolumn{2}{|c|}{$n=3302$} & \multicolumn{2}{|c|}{$n=2241$} & \multicolumn{2}{|c|}{$n=2443$} \\
\hline Extremely underweight & 1.7 & $1.3-2.4$ & 3.9 & $3.0-5.1$ & 1.3 & $0.7-2.2$ \\
\hline Underweight & 4.8 & $4.1-5.6$ & 7.3 & $6.0-8.8$ & 3.9 & $2.6-5.5$ \\
\hline Normal weight & 74.2 & $72.3-76.0$ & 77.9 & $75.4-80.3$ & 76.8 & $73.2-80.2$ \\
\hline Overweight & 9.7 & $8.5-11.0$ & 7.7 & $6.0-9.8$ & 7.6 & $5.3-10.4$ \\
\hline Obese & 9.6 & $8.4-10.8$ & 3.2 & $2.2-4.6$ & 10.3 & $7.3-13.2$ \\
\hline Total & \multicolumn{2}{|c|}{$n=6779$} & \multicolumn{2}{|c|}{$n=4535$} & \multicolumn{2}{|c|}{$n=4948$} \\
\hline Extremely underweight & 2.0 & $1.6-2.5$ & 3.4 & $2.7-4.2$ & 1.9 & $1.3-2.7$ \\
\hline Underweight & 5.1 & $4.5-5.8$ & 6.6 & $5.7-7.6$ & 4.6 & $3.4-5.8$ \\
\hline Normal weight & 74.0 & $72.6-75.4$ & 78.3 & $76.4-80.1$ & 74.7 & $71.8-77.5$ \\
\hline Overweight & 9.9 & $9.1-10.8$ & 7.7 & $6.6-9.0$ & 8.9 & $7.0-10.9$ \\
\hline Obese & 8.9 & $8.0-9.9$ & 4.0 & $3.2-5.0$ & 10.0 & $8.0-11.7$ \\
\hline
\end{tabular}



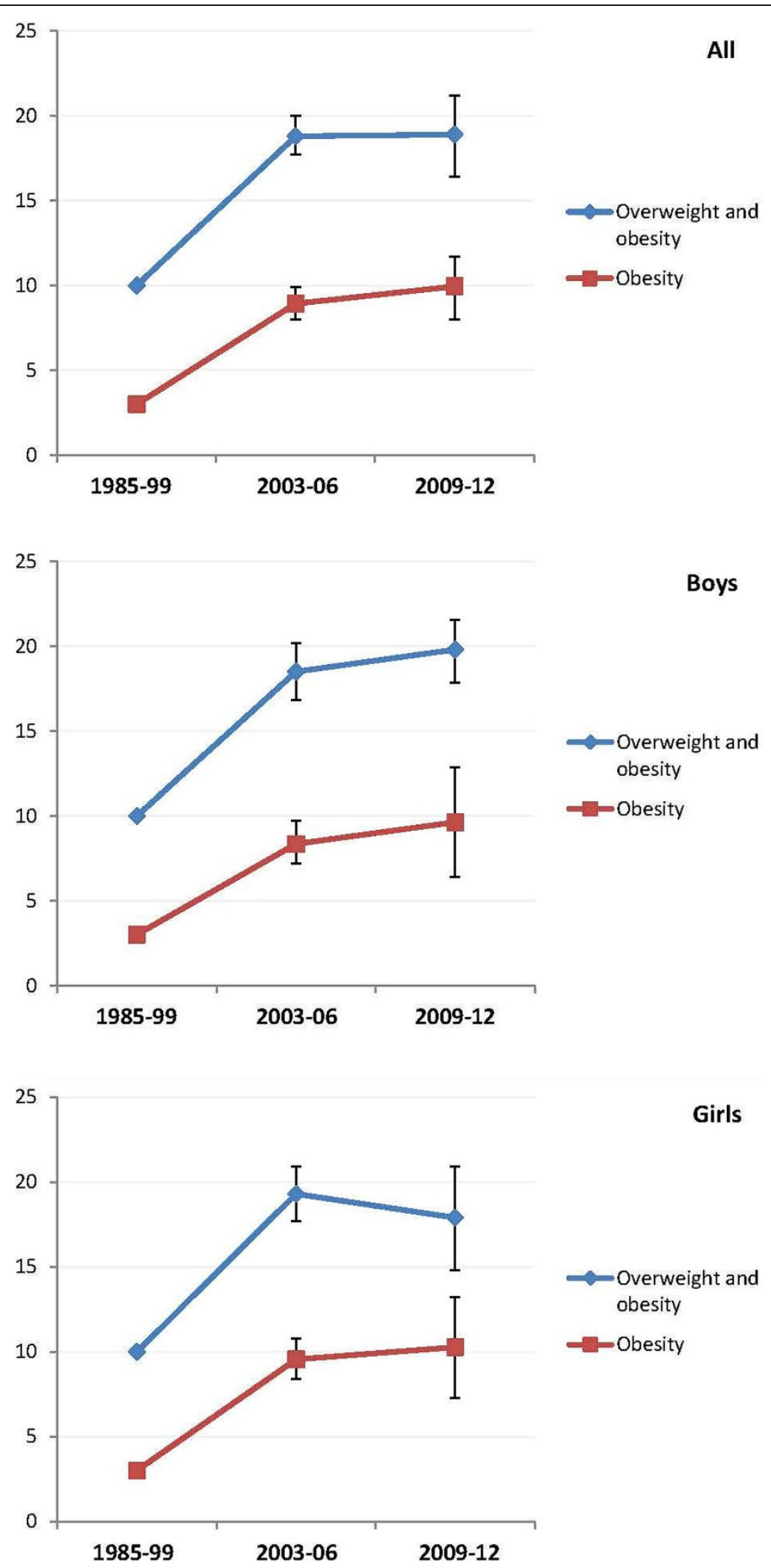

Fig. 1 Comparison of prevalence rates of obesity and overweight, including obesity, for adolescents aged 11 to 17 years over time with data derived from Kromeyer-Hauschild (1985-99) [18], KiGGS baseline survey (2003-06) and KiGGS Wave 1 (2009-12) 
children and adults on an international level [23, 24]. The growing number of obese adolescents and young adults is alarming. Overweight and obese adolescents are more likely to stay obese into adulthood $[25,26]$ and when they themselves become parents and stay overweight or obese, their children are again more likely to be overweight or obese [27]. This cycle of the obesity epidemic needs to be interrupted since overweight and obesity is often accompanied by an increased risk for noncommunicable diseases like cardiovascular diseases, diabetes, cancer, and mental health problems [28-30]. This indicates a need for the prevention of overweight and obesity. Since the age of leaving kindergarten and starting primary school has been identified as a critical period for the development of overweight [31, 32], early childhood offers an effective starting point for preventive interventions. To avoid the increase in the prevalence rate of overweight after school entry, prevention should take place, at the latest, during the kindergarten years [31].

On a national level, the action plan "IN FORM - German national initiative to promote healthy diets and physical activity" was implemented with the aim of achieving lasting improvements with regard to the health behaviour of the population [33]. For 2016, a law for the enhancement of health promotion and prevention is planned by the Federal Ministry of Health [34]. The health goal "growing up healthy" ("gesund aufwachsen") [35] is embedded in this law and gives hope for intensified actions.

This study has strengths and limitations. Strengths include the large sample size, the wide age range covered (11-17 years) and the fact that the study was based on a nationwide sample. A further strength is that a correction procedure was applied instead of the uncritical use of selfreported values. The comparison of corrected with uncorrected rates of KiGGS Wave 1 emphasises the need for a correction (e.g. after correction, the obesity rates in boys doubled and in girls, tripled). Due to the time lag and different interview modes between KiGGS baseline and KiGGS Wave 1, the method of the correction procedure Kurth and Ellert [10] developed was replicated with the self-reports derived from telephone-based KiGGS Wave 1 and the data of the measured values of a subsample. Furthermore, the existing correction procedure was extended to include missing values on self-reported height and/or weight, which occurred in $8 \%$ of the study population, and confidence intervals were added to the corrected prevalence rates.

One important limitation of this study is the time lag between the telephone interview where self-reported data of height and weight were collected and the physical examination of MoMo, where measurements were obtained. For the derivation of the correction factors, the sample was restricted to participants with a time lag of less than 3 months. A further limitation could be that
KiGGS Wave 1 was based on a longitudinal sample, thus the adolescents interviewed were part of the KiGGS cohort and were thus asked to participate in KiGGS for a second time. This could lead to a selection bias. However, the sample weights used in the analyses include a correction for the dropout probability. In the MoMo subsample, there might also be a selection bias that might even be stronger compared to the data of KiGGS Wave 1. Therefore, it was preferred to correct self-reports of KiGGS Wave 1 instead of using the measured values from the MoMo subsample. Still, there might be some selection bias left in the corrected prevalence rates, even after taking body perception and weight status based on selfreported values into account, so that the corrected prevalence rates for overweight and obesity might still be somewhat too low, but much less so than uncorrected rates. A further advantage of the larger sample size of KiGGS Wave 1 is increased stability of the estimated rates.

\section{Conclusion}

In German adolescents aged 11 to 17 years, a plateau in the prevalence rate of overweight, including obesity, has been reached, but the rates still remain at a high level. For obesity, there is still a slight tendency for an increase (n.s.) in the prevalence seen. This emphasises the significance of this health issue and the need for prevention of overweight and obesity in children and adolescents.

\section{Abbreviations}

BMI: Body mass index; DEGS1: German health interview and examination survey for adults; KiGGS: German health interview and examination survey for children and adolescents; MoMo: Motorik Modul.

\section{Competing interests}

The authors declare that they have no competing interests.

\section{Authors' contributions}

AKB performed the statistical analyses and wrote the manuscript. ASR, BMK and UE made substantial contributions, revised the manuscript critically and counselled AKB on statistical questions. BMK is the principal investigator of KiGGS and developed together with UE the correction procedure applied in this article. AKB, ASR, RK and UE were involved in data assessment and data-validation process. ASR and RK developed the weighing factor. SS is contributor of the 'Motorik Modul' MoMo and was involved in data collection and data assessment. SW revised the manuscript critically. All authors have read and approved the final version.

\section{Acknowledgements}

The KiGGS study was funded by the German Federal Ministry of Health, the Ministry of Education and Research, and the Robert Koch Institute. The authors thank all participants and their parents for participating in the telephone-interview as well as all the colleagues at the Robert Koch Institute that were involved in conducting the study. The authors would also like to thank the team of the 'Motorik-Modul' (MoMo) for providing measurements of height and weight of a subsample of the KiGGS participants.

\section{Author details}

'Department of Epidemiology and Health Monitoring, Robert Koch Institute, General-Pape-Str. 62-66, 12101 Berlin, Germany. 'Department of Sports and Sports Science, Karlsruhe Institute of Technology, Engler-Bunte-Ring 15, 76131 Karlsruhe, Germany. ${ }^{3}$ Department of Pediatric Endocrinology and Diabetology, Charité Universitätsmedizin Berlin, Augustenburger Platz 1, 13353 Berlin, Germany. 
Received: 3 April 2015 Accepted: 31 October 2015

Published online: 06 November 2015

\section{References}

1. Kurth BM, Kamtsiuris P, Holling H, Schlaud M, Dolle R, Ellert U, et al. The challenge of comprehensively mapping children's health in a nation-wide health survey: design of the German KiGGS-Study. BMC Public Health. 2008:8:196.

2. Kurth BM, Schaffrath Rosario A. The prevalence of overweight and obese children and adolescents living in Germany. Results of the German Health Interview and Examination Survey for Children and Adolescents (KiGGS). Bundesgesundheitsblatt Gesundheitsforschung Gesundheitsschutz. 2007:50(5-6):736-43.

3. Wabitsch M, Moss A, Kromeyer-Hauschild K. Unexpected plateauing of childhood obesity rates in developed countries. BMC Med. 2014;12:17.

4. Lobstein T, Jackson-Leach R, Moodie ML, Hall KD, Gortmaker SL, Swinburn BA, et al. Child and adolescent obesity: part of a bigger picture. Lancet. 2015;385(9986):2510-20.

5. Bluher S, Meigen C, Gausche R, Keller E, Pfaffle R, Sabin M, et al. Age-specific stabilization in obesity prevalence in German children: a cross-sectional study from 1999 to 2008. Int J Pediatr Obes. 2010;6(2-2):e199-206.

6. Moss A, Klenk J, Simon K, Thaiss H, Reinehr T, Wabitsch M. Declining prevalence rates for overweight and obesity in German children starting school. Eur J Pediatr. 2012;171(2):289-99.

7. Lange M, Butschalowsky HG, Jentsch F, Kuhnert R, Schaffrath Rosario A, Schlaud M, et al. The first KiGGS follow-up (KiGGS Wave 1): study conduct, sample design, and response. Bundesgesundheitsblatt Gesundheitsforschung Gesundheitsschutz. 2014;57(7):747-61.

8. Brettschneider AK, Schaffrath Rosario A, Ellert U. Validity and predictors of BMI derived from self-reported height and weight among 11- to 17-year-old German adolescents from the KiGGS study. BMC Res Notes. 2011;4(1):414.

9. Jansen W, van de Looij-Jansen PM, Ferreira I, de Wilde EJ, Brug J. Differences in measured and self-reported height and weight in Dutch adolescents. Ann Nutr Metab. 2006;50(4):339-46.

10. Kurth B, Ellert U. Estimated and measured BMI and self perceived body image of adolescents in Germany: part 1: general implications for correcting prevalence estimations of overweight and obesity. Obes Facts. 2010;3:181-90.

11. Strauss RS. Comparison of measured and self-reported weight and height in a cross-sectional sample of young adolescents. Int J Obes Relat Metab Disord. 1999;23(8):904-8.

12. Kurth BM, Ellert U. Perceived or true obesity: which causes more suffering in adolescents? Findings of the German Health Interview and Examination Survey for Children and Adolescents (KiGGS). Dtsch Arztebl Int. 2008;105(23):406-12.

13. Brettschneider AK, Schaffrath Rosario A, Wiegand S, Kollock M, Ellert U. Development and validation of correction formulas for self-reported height and weight to estimate BMI in adolescents. Results from the KiGGS study. Obes Facts. 2015;8:30-42.

14. Ellert U, Brettschneider AK, Wiegand S, Kurth BM. Applying a correction procedure to the prevalence estimates of overweight and obesity in the German part of the HBSC study. BMC Res Notes. 2014;7:181.

15. Wick K, Holling H, Schlack R, Bormann B, Brix C, Sowa M, et al. Self-assessment of BMI data : verification of the practicability of a correction formula on a sample of 11- to 13-year-old girls. Bundesgesundheitsblatt Gesundheitsforschung Gesundheitsschutz. 2011;54(6):752-9.

16. Robert Koch-Institut (RKI). KiGGS - Health Survey for Children and Adolescents Wave 1 - Projectdescription. Berlin: Robert Koch-Institut (RKI); 2011.

17. Hölling H, Schlack R, Kamtsiuris P, Butschalowsky H, Schlaud M, Kurth BM. The KiGGS study. Nationwide representative longitudinal and cross-sectional study on the health of children and adolescents within the framework of health monitoring at the Robert Koch Institute. Bundesgesundheitsblatt Gesundheitsforschung Gesundheitsschutz. 2012;55(6-7):836-42.

18. Kromeyer-Hauschild K, Wabitsch M, Kunze D, Geller F, Geiß HC, Hesse V, et al. Percentiles of body mass index in children and adolescents evaluated from different regional German studies. Monatsschr Kinderheilkd. 2001;149:807-18.

19. Currie C, Samdal O, Boyce W, Smith R. Health behaviour in school-aged children: a WHO cross-national study (HBSC), Research Protocol for the 2001/2002 Survey. Child and Adolescent Health Research Unit (CAHRU). University of Edinburgh: Copenhagen, Denmark; 2001.
20. Lampert T, Muters S, Stolzenberg H, Kroll LE, Ki GGSSG. Measurement of socioeconomic status in the KiGGS study: first follow-up (KiGGS Wave 1). Bundesgesundheitsblatt Gesundheitsforschung Gesundheitsschutz. 2014;57(7):762-70.

21. Wolter K. Introduction to variance estimation. 2nd ed. New York: Springer; 2007.

22. Mensink GB, Schienkiewitz A, Haftenberger M, Lampert $T$, Ziese T, Scheidt-Nave C. Overweight and obesity in Germany: results of the German Health Interview and Examination Survey for Adults (DEGS1). Bundesgesundheitsblatt Gesundheitsforschung Gesundheitsschutz. 2013;56(5-6):786-94

23. Skinner AC, Skelton JA. Prevalence and trends in obesity and severe obesity among children in the United States, 1999-2012. JAMA Pediatr. 2014;168(6):561-6.

24. von Ruesten A, Steffen A, Floegel A, van der A DL, Masala G, Tjonneland A, et al. Trend in obesity prevalence in European adult cohort populations during follow-up since 1996 and their predictions to 2015. PLoS One. 2011;6(11):e27455.

25. Singh AS, Mulder C, Twisk JW, van Mechelen W, Chinapaw MJ. Tracking of childhood overweight into adulthood: a systematic review of the literature. Obes Rev. 2008;9(5):474-88.

26. Gordon-Larsen P, The NS, Adair LS. Longitudinal trends in obesity in the United States from adolescence to the third decade of life. Obesity (Silver Spring, Md). 2010;18(9):1801-4.

27. Kleiser C, Schaffrath Rosario A, Mensink GB, Prinz-Langenohl R, Kurth BM. Potential determinants of obesity among children and adolescents in Germany: results from the cross-sectional KiGGS Study. BMC Public Health. 2009;9:46.

28. Baumeister $\mathrm{H}$, Harter M. Mental disorders in patients with obesity in comparison with healthy probands. Int J Obes. 2007;31(7):1155-64.

29. Schienkiewitz A, Mensink GB, Scheidt-Nave C. Comorbidity of overweight and obesity in a nationally representative sample of German adults aged 18-79 years. BMC Public Health. 2012;12:658.

30. Renehan AG, Tyson M, Egger M, Heller RF, Zwahlen M. Body-mass index and incidence of cancer: a systematic review and meta-analysis of prospective observational studies. Lancet. 2008;371(9612):569-78.

31. Hoffmann SW, Ulrich R, Simon P. Refined analysis of the critical age ranges of childhood overweight: implications for primary prevention. Obesity (Silver Spring, Md). 2012;20(10):2151-4.

32. Kurth BM, Schaffrath Rosario A. Overweight and obesity in children and adolescents in Germany. Bundesgesundheitsblatt Gesundheitsforschung Gesundheitsschutz. 2010;53(7):643-52.

33. Federal Ministry of Food and Agriculture \& Federal Ministry of Health. IN FORM - German national initiative to promote healthy diets and physical activity. Berlin: Federal Ministry of Food and Agriculture \& Federal Ministry of Health; 2013.

34. Federal Ministry of Health. Draft for a law to enhance health promotion and prevention (PrävG). 2014

35. Federal Ministry of Health. National Health Goal: growing up healthy: life skills, exercise, nutrition. Berlin: Federal Ministry of Health; 2010.

\section{Submit your next manuscript to BioMed Central and take full advantage of:}

- Convenient online submission

- Thorough peer review

- No space constraints or color figure charges

- Immediate publication on acceptance

- Inclusion in PubMed, CAS, Scopus and Google Scholar

- Research which is freely available for redistribution 